\title{
Contribution of sickle cell disease to the occurrence of developmental disabilities: A population-based study
}

\author{
Allison Ashley-Koch, $P h D^{1}$, Catherine C. Murphy, $M P H^{2}$, Muin J. Khoury, MD, $P h D^{1}$, and Coleen A. Boyle, $P h D^{2}$
}

\begin{abstract}
Purpose: Population-based surveillance of children aged 3-10 years from metropolitan Atlanta was used to determine if stroke-related neurological damage in children with sickle cell disease (SCD) is associated with developmental disabilities (DD). Methods: School and medical records were reviewed annually to identify eligible children. Observed-to-expected ratios, $P$ values, and population attributable fractions were calculated. Results: Children with $\mathrm{SCD}$ had increased risk for $\mathrm{DD}(\mathrm{O} / \mathrm{E}=3.2, P<0.0001)$, particularly mental retardation $(\mathrm{O} / \mathrm{E}=2.7$, $P=0.0005)$ and cerebral palsy $(0 / E=10.8, P<0.0001)$. This risk was confined to $D D$ associated with stroke $(\mathrm{O} / \mathrm{E}=130, P<0.0001$; for $\mathrm{DD}$ without stroke: $\mathrm{O} / \mathrm{E}=1.3, P=0.23)$. Conclusions: Children with $\mathrm{SCD}$ have increased risk for DD associated with stroke; thus, aggressive interventions are needed to prevent stroke in these children. Genetics in Medicine, 2001:3(3):181-186.
\end{abstract}

Key Words: sickle cell disease, developmental disabilities, stroke, epidemiology, surveillance

Sickle cell disease (SCD) is a collection of autosomal recessive genetic disorders characterized by a hemoglobin variant called sickle hemoglobin ( $\mathrm{Hb} \mathrm{S}$ ). The $\mathrm{Hb} \mathrm{S}$ variant is caused by a substitution of valine for glutamic acid at the sixth amino acid position in the beta globin gene. All individuals who are homozygous or compound heterozygous for $\mathrm{Hb} \mathrm{S}$ exhibit some clinical manifestations of SCD. Individuals homozygous for $\mathrm{Hb} \mathrm{S}$ exhibit the most severe form of SCD. ${ }^{1}$ Individuals who are $\mathrm{Hb} \mathrm{S}$ compound heterozygotes with other hemoglobin variants, such as $\mathrm{Hb} \mathrm{C}$ and $\beta^{+}$-thalassemia, generally have a less severe course of the disease. However, individuals who have $\mathrm{Hb} S$ in combination with $\beta^{0}$-thalassemia often have severe expression of the disease. ${ }^{1} \mathrm{SCD}$ can be quite debilitating. Symptoms include chronic anemia, acute chest syndrome, pain crises, splenic and renal dysfunction, susceptibility to bacterial infections and stroke. ${ }^{2}$

When compared with the general population, children with SCD have a particularly high risk for stroke, especially for cerebrovascular infarctions. ${ }^{3-5}$ Approximately $5-10 \%$ of children with SCD have a clinical history of stroke, $, 5,6$ and without transfusion intervention, as many as $50-70 \%$ of those children experience recurrent strokes.,7 In addition, magnetic resonance imaging (MRI) and computed tomographic (CT) scans

From the ${ }^{1}$ Office of Genetics and Disease Prevention, National Center for Environmental Health, Centers for Disease Control and Prevention, Atlanta, Georgia, and ${ }^{2}$ National Center for Birth Defects and Developmental Disabilities, Centers for Disease Control and Prevention, Atlanta, Georgia.

Allison Ashley-Koch, PhD, Center for Human Genetics, Duke University Medical Center, 051 CARL Building, Durham, NC 27710.

Received: November 13, 2000.

Accepted: January 30, 2001. reveal that $4-18 \%$ of children with SCD who do not have a clinical history of stroke have experienced silent cerebrovascular infarctions. ${ }^{6,8-10}$ Together, these data suggest that up to $30 \%$ of all children with SCD experience some type of cerebrovascular insult. However, since the risk estimates of these studies were performed on clinically referred populations, the actual risk for stroke among children with SCD needs to be assessed in a population-based analysis.

There is some evidence that neurological damage is associated with strokes among children with SCD. It has been shown that children with SCD who have experienced a clinically recognized stroke are cognitively impaired when compared with unaffected siblings. ${ }^{11}$ The cognitive impairment appears to be due to stroke and not to the disease itself. That is, children with SCD who have experienced stroke are also cognitively impaired when compared with other children with SCD who have not experienced a stroke. ${ }^{6,11,12}$ Moreover, children with SCD who do not have cerebrovascular abnormalities (as detected by MRI) do not appear to have cognitive deficits. ${ }^{11}$ Studies using MRI and CT scans to identify children with silent cerebrovascular infarctions have noted that these children are also cognitively impaired when compared with unaffected children. ${ }^{6,11}$ However, the impairment among children with silent strokes is not as severe as it is among the children who have experienced clinical strokes. Results from a few studies have suggested that the disease itself is a risk factor for cognitive impairment. Subtle neuropsychological deficits were observed among children with SCD who do not have a clinical history of stroke when they were compared with unaffected children. ${ }^{13,14}$ However, these studies did not use diagnostic methods, such as MRI and CT scans, to detect the presence of silent cerebrovascular infarctions. Recently, a study did find evidence of cognitive def- 
icit among children with SCD who did not have abnormalities detected by MRI. ${ }^{15}$ The authors suggested that cognitive deficits in the absence of stroke could be due to chronic hypoxia of brain tissue.

Although the studies mentioned above performed extensive batteries of tests to determine the specific neurological deficits of children with SCD in the presence or absence of stroke, none of the studies was population-based. Thus, none of the studies was able to estimate the magnitude of the association between SCD and cognitive deficits associated with stroke. In the present analysis, we have examined the contribution of SCD to the occurrence of specific developmental disabilities (DD) associated with and without stroke in a population-based study of developmental disabilities among 3- to 10-year-old children.

\section{METHODS}

\section{Study population}

The Metropolitan Atlanta Developmental Disabilities Surveillance Program (MADDSP) ascertained children 3-10 years of age who resided in the five county (Clayton, Cobb, DeKalb, Fulton, Gwinnett) metropolitan Atlanta area during 19911993 and who had at least one of the following developmental disabilities: ${ }^{16}$

Mental retardation (MR): an intelligence quotient (IQ) of 70 or less on the most recent, individually administered standardized psychometric test or, in the absence of an IQ test, a written statement by a psychometrist that a child's intellectual functioning falls within this range.

Cerebral palsy (CP): nonprogressive, but often changing, motor impairment syndromes secondary to lesions or anomalies of the brain arising at any time during brain development as diagnosed by a qualified physician or from physical findings by other qualified health care professional (e.g., physical or occupational therapist) and confirmed by a MADDSP developmental pediatrician. It does not include motor disorders that are transient, that result from progressive disease of the brain, or are due to spinal cord abnormalities or injuries.

Hearing impairment (HI): measured, bilateral, pure-tone hearing loss at frequencies of 500, 1,000, and 2,000 Hz averaging 40 decibels or more, unaided, in the better ear or, in the absence of measured hearing loss, a description, provided by a certified audiologist or physician, of a hearing loss of 40 decibels or more in the better ear (e.g., profound sensorineural hearing loss).

Visual impairment (VI): measured visual acuity of 20/70 or worse, with correction in the better eye or, in the absence of measured visual acuity, a statement by an eye specialist of either (1) a functional description of visual acuity of 20/70 or worse, (2) low vision or blindness, or (3) cortical blindness.

Most children eligible for MADDSP were identified from a review of the records from special education programs in the public schools serving the five county metropolitan Atlanta area or from other Georgia Department of Education programs for children with DD. Additional sources reviewed to identify eligible children included facilities of the Georgia Department of Human Resources that provide services for children with DD, as well as pediatric and public hospitals and clinics in the metropolitan Atlanta area. School and medical records were reviewed annually to identify eligible children. Once a child was identified as eligible, medical and demographic data were collected from the records. Many children met the eligibility status for the program for multiple years. In the present analysis, we counted each child once, regardless of the number of years a child met eligibility criteria.

\section{Statistical methods}

Using medical data obtained from the children's records, we used the International Classification of Diseases, 9th Revision (ICD-9) code 282.6 to identify the number of children in MADDSP with SCD. Because all of the children with SCD were black, we restricted our analysis to black children with DD. We determined the expected numbers of children with SCD using the observed number of black children in MADDSP and the expected frequency of SCD in the black population $(1 / 375){ }^{2}$ Information concerning the children with strokes did not always specify the type of stroke (hemorrhagic or infarctive). Thus, for the purposes of our analyses, we identified children with stroke by ICD- 9 code 436 . We generated observed to expected ratios with confidence intervals (CIs) and one-sided $P$ values based on the Poisson distribution using the Statistical Analysis Battery for Epidemiologic Research (SABER). ${ }^{17}$ Population attributable fractions calculated by the Miettinen formula $^{18}$ were used to estimate the contribution of SCD to the occurrence of DD among 3- to10-year-old black children in Atlanta.

\section{RESULTS}

During the 1991-1993 study years, in metropolitan Atlanta there were 22 children with SCD among 2,566 black children aged 3 to 10 years with developmental disabilities. Of those 22 children, 14 (64\%) were male, 16 (73\%) had MR, 14 (64\%) had CP, $1(4.5 \%)$ had HI, and 1 (4.5\%) had VI. Thirteen $(59 \%)$ of these children had a history of stroke and 9 (41\%) exhibited multiple disabilities. A summary of the clinical and demographic characteristics of the children with SCD is shown in Table 1.

First, we determined if, in general, there were more children with SCD and any DD than would be expected in this population. The results of this analysis are summarized in Table 2. Overall, the observed to expected (Obs/Exp) ratio for SCD and any DD was 3.2 (95\% CI: $2.0-4.9, P<0.0001)$ among 3 - to 10 -year-old black children in metropolitan Atlanta. This association between SCD and DD was not limited to either sex (Table 2).

We next examined whether SCD was associated with a specific DD (Table 3). Results revealed statistically significant associations between SCD and MR and CP, with Obs/Exp ratios of 2.7 (95\% CI: 1.5-4.4, $P=0.0005)$ and 10.8 (95\% CI: 5.9$18.0, P<0.0001$ ), respectively. SCD contributes to $0.4 \%$ of MR 
Table 1

Clinical and demographic features of the children with sickle cell disease in the Metropolitan Atlanta Developmental Disabilities Surveillance Program, 1991-1993

\begin{tabular}{|c|c|c|c|c|c|c|c|}
\hline Case & Sex & $\begin{array}{l}\text { Mental } \\
\text { retardation }\end{array}$ & $\begin{array}{c}\text { Cerebral } \\
\text { palsy }\end{array}$ & $\begin{array}{c}\text { Hearing } \\
\text { impair- } \\
\text { ment }\end{array}$ & $\begin{array}{c}\text { Visual } \\
\text { impair- } \\
\text { ment }\end{array}$ & Stroke & $\begin{array}{l}\text { Age at } \\
\text { stroke }\end{array}$ \\
\hline 1 & $\mathrm{f}$ & $\mathrm{x}$ & $\mathrm{x}$ & & & $\mathrm{x}$ & $2 \mathrm{yr}, 7 \mathrm{yr}$ \\
\hline 2 & $\mathrm{~m}$ & $\mathrm{x}$ & $\mathrm{x}$ & & & $\mathrm{x}$ & $4 \mathrm{yr}$ \\
\hline 3 & $\mathrm{f}$ & $\mathrm{x}$ & $\mathrm{x}$ & & & $\mathrm{x}$ & $9 \mathrm{yr}$ \\
\hline 4 & $\mathrm{f}$ & $\mathrm{x}$ & & & & & \\
\hline 5 & $\mathrm{~m}$ & & $\mathrm{x}$ & & & & \\
\hline 6 & $\mathrm{f}$ & & $\mathrm{x}$ & & & & \\
\hline 7 & $\mathrm{~m}$ & $\mathrm{x}$ & & & & & \\
\hline 8 & $\mathrm{~m}$ & $\mathrm{x}$ & $\mathrm{x}$ & & & $\mathrm{x}$ & $2 \mathrm{yr}$ \\
\hline 9 & $\mathrm{f}$ & $\mathrm{x}$ & & & & & \\
\hline 10 & $\mathrm{~m}$ & $\mathrm{x}$ & & & & & \\
\hline 11 & $\mathrm{~m}$ & $\mathrm{x}$ & & & & & \\
\hline 12 & $\mathrm{~m}$ & & $\mathrm{x}$ & & & $\mathrm{x}$ & $4 \mathrm{yr}$ \\
\hline 13 & $\mathrm{f}$ & $\mathrm{x}$ & & & & $\mathrm{x}$ & $6 \mathrm{yr}$ \\
\hline 14 & $\mathrm{~m}$ & & $\mathrm{x}$ & & & $\mathrm{x}$ & $4 \mathrm{yr}$ \\
\hline 15 & $\mathrm{f}$ & & $\mathrm{x}$ & & & $\mathrm{x}$ & $3 \mathrm{yr}$ \\
\hline 16 & $\mathrm{f}$ & & $\mathrm{x}$ & & & $\mathrm{x}$ & $5 \mathrm{yr}$ \\
\hline 17 & $\mathrm{~m}$ & $\mathrm{x}$ & $\mathrm{x}$ & & & $\mathrm{x}$ & $<1 \mathrm{yr}$ \\
\hline 18 & $\mathrm{~m}$ & $\mathrm{x}$ & $\mathrm{x}$ & & & $\mathrm{x}$ & $1 \mathrm{yr}$ \\
\hline 19 & $\mathrm{~m}$ & $\mathrm{x}$ & $\mathrm{x}$ & & $\mathrm{x}$ & $\mathrm{x}$ & $3 \mathrm{yr}$ \\
\hline 20 & $\mathrm{~m}$ & $\mathrm{x}$ & & & & & \\
\hline 21 & $\mathrm{~m}$ & $\mathrm{x}$ & & $\mathrm{x}$ & & & \\
\hline 22 & $\mathrm{~m}$ & $\mathrm{x}$ & $\mathrm{x}$ & & & $\mathrm{x}$ & $2 \mathrm{yr}, 3 \mathrm{yr}$ \\
\hline
\end{tabular}

Table 2

Association between sickle cell disease and developmental disabilities among black children aged 3-10 years, metropolitan Atlanta, 1991-1993

\begin{tabular}{lccc}
\hline & Males & Females & Total \\
\hline No. of children & 1,604 & 962 & 2,566 \\
Observed & 14 & 8 & 22 \\
Expected & 4.3 & 2.6 & 6.8 \\
Observed/expected & 3.3 & 3.1 & 3.2 \\
$\left(\begin{array}{l}95 \% \text { CI }) \\
P \text { value }\end{array}\right.$ & $(1.8-5.5)$ & $(1.3-6.1)$ & $(2.0-4.9)$ \\
$\begin{array}{l}\text { Population attributable } \\
\text { fraction (\%) }\end{array}$ & 0.0002 & 0.005 & $<0.0001$ \\
\hline
\end{tabular}

among black children and to $2.6 \%$ of CP among black children. We did not observe statistically significant associations between SCD and HI or VI, although the numbers of children with these disabilities were small (Table 3 ).
Table 3

Association between sickle cell disease and specific developmental disabilities among black children aged 3-10 years, metropolitan Atlanta, 1991-1993

\begin{tabular}{|c|c|c|c|c|}
\hline & $\begin{array}{l}\text { Mental } \\
\text { retardation }\end{array}$ & $\begin{array}{c}\text { Cerebral } \\
\text { palsy }\end{array}$ & $\begin{array}{c}\text { Hearing } \\
\text { impairment }\end{array}$ & $\begin{array}{c}\text { Visual } \\
\text { impairment }\end{array}$ \\
\hline No. of children & 2,243 & 488 & 162 & 135 \\
\hline Observed & 16 & 14 & 1 & 1 \\
\hline Expected & 6.0 & 1.3 & 0.4 & 0.4 \\
\hline Observed/expected & 2.7 & 10.8 & 2.3 & 2.8 \\
\hline$(95 \% \mathrm{CI})$ & $(1.5-4.4)$ & $(5.9-18.1)$ & $(0.1-13.0)$ & $(0.1-15.5)$ \\
\hline$P$ value & 0.0005 & $<0.0001$ & 0.33 & 0.33 \\
\hline $\begin{array}{l}\text { Population } \\
\text { attributable } \\
\text { fraction (\%) }\end{array}$ & 0.4 & 2.6 & 0.3 & 0.5 \\
\hline
\end{tabular}

Table 4

Association between sickle cell disease and level of mental retardation among black children aged 3-10 years, metropolitan Atlanta, 1991-1993

\begin{tabular}{|c|c|c|c|}
\hline & $\begin{array}{c}\text { Mild MR } \\
(\mathrm{IQ}=50-70)\end{array}$ & $\begin{array}{l}\text { Severe MR } \\
(\mathrm{IQ}<50)\end{array}$ & $\begin{array}{l}\text { MR: unknown } \\
\text { level }\end{array}$ \\
\hline No. of children & 1,399 & 668 & 176 \\
\hline Observed & 7 & 8 & 1 \\
\hline Expected & 3.7 & 1.8 & 0.5 \\
\hline Observed/expected & 1.9 & 4.5 & 2.1 \\
\hline$(95 \% \mathrm{CI})$ & $(0.8-3.9)$ & $(1.9-8.9)$ & $(0.1-11.9)$ \\
\hline$P$ value & 0.08 & 0.0006 & 0.39 \\
\hline $\begin{array}{l}\text { Population attributable } \\
\text { fraction (\%) }\end{array}$ & 0.2 & 0.9 & 0.3 \\
\hline
\end{tabular}

Based on level of MR, there were 4.5 (95\% CI: 1.9-8.9, $P=$ $0.0006)$ times the expected number of children with SCD and severe MR (IQ < 50) and 1.9 (95\% CI: $0.8-3.9, P=0.08)$ times the expected number of children with SCD and mild MR $(\mathrm{IQ}=50-70)($ Table 4$)$. Almost $1 \%$ of severe MR among black children is attributed to SCD in this population.

Analyses of maternal sociodemographic factors were performed on a subset of the MADDSP data set: those children born in the metropolitan Atlanta area for whom demographic data were available. For maternal education $(<12$ years vs. $\geq 12$ years), the observed to expected ratios were 2.8 (95\% CI: $0.9-6.4$ ) for children born to mothers with $<12$ years of education and 3.0 (95\% CI: 1.4-5.5) for children born to mothers with 12 or more years of education. Both ratios were of similar magnitude and statistically significant at $P<0.05$. Therefore, the association between SCD and DD was not restricted to a particular maternal education level in our population. Next, we stratified the population on the basis of maternal age $(<35$ years vs. $\geq 35$ years). The Obs/Exp ratio was higher for children with SCD born to older mothers ( $\geq 35$ years) $(5.3,95 \%$ CI: 0.6-19.0) than for children with SCD born to younger mothers ( $<35$ years) $(2.9,95 \%$ CI: $1.5-4.9)$, but the ratio for older 
mothers was not statistically significant $(P=0.06$ older mothers, $P<0.001$ younger mothers).

We examined our population to determine whether the association between SCD and DD could be attributed to the presence of stroke. The results of this analysis, shown in Table 5, suggest that the association between SCD and DD is almost entirely due to the presence of stroke. The Obs/Exp ratio of the children with stroke was 130 (95\% CI: 69-222, $P<0.0001$ ) compared with the statistically nonsignificant $1.3 \mathrm{Obs} / \mathrm{Exp}$ ratio (95\% CI: $0.6-2.5, P=0.23$ ) of the children without stroke. Among the black children who had a DD associated with stroke, the population attributable fraction of SCD was 34\%. Thus, about a third of the cases of stroke-related DD among black children was due to SCD.

Examination of the age at which stroke occurred for the children with SCD indicated that 10/13 (77\%) of the children experienced a stroke before the age of 5 years (Table 1). In order to determine if the association between SCD and DD with stroke was restricted by the age at stroke, we stratified the population based on whether or not the stroke occurred before age 5 and computed the Obs/Exp ratios (Table 5). The results showed that there were more children with SCD and DD with stroke than would be expected, regardless of the age at which the stroke had occurred.

Of the children with SCD, $41 \%$ exhibited multiple DD. There were 8.7 (95\% CI: 4.0-16.4, $P<0.0001$ ) times the expected number of children with SCD and multiple DD (Table 6). Of the children with SCD and multiple DD who had experienced a stroke $(N=8)$, seven children had MR and $\mathrm{CP}$, and one child had MR, CP, and VI. Further examination of the children with multiple disabilities indicated that this association was also due to the presence of stroke (Table 6). Among black children, $38 \%$ of those with multiple DD who had experienced a stroke also had SCD.

To determine whether or not stroke was causal for the DD in the children with SCD and stroke, we examined the diagnostic dates for both the stroke and the DD. For all children with SCD who had experienced a stroke $(N=13)$, either the diagnostic date of the stroke preceded the date of the DD diagnosis $(N=$
Table 6

Association between sickle cell disease and multiple developmental disabilities with stroke among black children aged 3-10 years, metropolitan Atlanta, 1991-1993

\begin{tabular}{lccc}
\hline & $\begin{array}{c}\text { Multiple } \\
\text { developmental } \\
\text { disabilities }\end{array}$ & $\begin{array}{c}\text { Multiple } \\
\text { developmental } \\
\text { disabilities with } \\
\text { stroke }\end{array}$ & $\begin{array}{c}\text { Multiple } \\
\text { developmental } \\
\text { disabilities without } \\
\text { stroke }\end{array}$ \\
\hline No. of children & 391 & 21 & 370 \\
Observed & 9 & 8 & 1 \\
Expected & 1.0 & 0.1 & 1.0 \\
Observed/expected & 8.7 & 133 & 1.0 \\
$\begin{array}{l}\text { (95\% CI) } \\
P \text { value }\end{array}$ & $(4.0-16.4)$ & $(58-263)$ & $(0.3-5.6)$ \\
Population & $<0.0001$ & $<0.0001$ & 0.63 \\
attributable & 2 & 38 & $<0.1$ \\
fraction (\%) & & & \\
\hline
\end{tabular}

8 ) or was concurrent with it $(N=5)$. This finding strongly suggests that the strokes were causal for the DD among these children.

\section{DISCUSSION}

The purpose of this population-based study was to measure the contribution of sickle cell disease to developmental disabilities associated with the presence or absence of stroke. Using children identified through the Metropolitan Atlanta Developmental Disabilities Surveillance Program, we were able to specifically examine the association of sickle cell disease with mental retardation, cerebral palsy, hearing impairment, and visual impairment. Our results suggest that, among black children, $0.6 \%$ of these four developmental disabilities can be attributed to SCD. When examining each developmental disability separately, we found that $2.6 \%$ of cerebral palsy and almost $1 \%$ of severe MR (IQ < 50) among black children can be attributed to SCD. Although these numbers may not appear to be signif-

Table 5

Association between sickle cell disease and developmental disabilities according to the presence of stroke and stratified by age at stroke among black children aged 3-10 years, metropolitan Atlanta, 1991-1993

\begin{tabular}{|c|c|c|c|c|}
\hline & $\begin{array}{l}\text { Developmental disability } \\
\text { without stroke }\end{array}$ & $\begin{array}{l}\text { Developmental disability } \\
\text { with stroke }\end{array}$ & $\begin{array}{c}\text { Developmental disability } \\
\text { with stroke at less than } \\
5 \text { years of age }\end{array}$ & $\begin{array}{c}\text { Developmental disability } \\
\text { with stroke at } 5-10 \text { years } \\
\text { of age }\end{array}$ \\
\hline No. of children & 2,528 & 38 & 28 & 4 \\
\hline Expected & 6.7 & 0.1 & 0.07 & 0.01 \\
\hline Observed/expected & 1.3 & 130 & 143 & 300 \\
\hline$P$ value & 0.23 & $<0.0001$ & $<0.0001$ & $<0.0001$ \\
\hline Population attributable fraction (\%) & $<0.1$ & 34 & 35 & 75 \\
\hline
\end{tabular}


icant, once the population is stratified on the presence or absence of stroke, the association between SCD and DD becomes extremely strong. Among black children residing in metropolitan Atlanta, 34\% of DD associated with stroke and 38\% of multiple DD associated with stroke were attributable to SCD. In contrast, SCD contributes to less than $0.1 \%$ of DD and multiple DD unrelated to stroke among black children. Thus, the increased risk for DD among black children with SCD is almost entirely due to the presence of stroke.

The contribution of SCD related stroke to DD in the black population is probably even greater than what we have estimated here. First, we did not account for mortality in children with SCD. Using death certificate data, one study estimated that the mortality rate for children with SCD who were 1-4 years old in Georgia during 1981-1992 was 1.05 per 100 person years. ${ }^{19}$ Thus, some children with SCD may have died before they reached eligibility for inclusion in the MADDSP. Second, we were unable to perform diagnostic procedures to detect the presence of silent cerebral infarctions. Approximately 4-18\% of all children with SCD experience silent cerebral infarctions ${ }^{6,8-10}$ and silent cerebral infarctions are associated with cognitive deficits. ${ }^{6,11}$ Children with SCD who experienced silent cerebral infarctions would not have been classified as having a stroke in our analysis, unless they also experienced a clinically recognized stroke. Finally, since we had restricted our definition of stroke to ICD-9 code 436, we did not have complete ascertainment of all the children in the MADDSP who had experienced a stroke. Specifically, the child representing Case 5 (Table 1) had experienced a hemorrhagic stroke that was coded as ICD-9 code 430. Thus, in our analysis he was not included as having stroke. For these reasons, we may have underestimated the contribution of sickle cell related stroke to $\mathrm{DD}$ in the black population.

Those children with SCD and stroke who were ascertained through the surveillance program had an average onset of stroke at 3.5 years. This age is younger than the 6- to 7-year average onset reported previously., ${ }^{5}$ However, our cohort ranged in age from 3 to 10 years and the children in the other studies ranged in age from 0 to 20 years ${ }^{5}$ and 5 to 18 years. ${ }^{12}$ Although we cannot say that the average age of onset of stroke is younger than previously reported, we can say that schoolaged children with SCD are experiencing stroke at very young ages and are severely impaired as a result. Others have documented this observation as well. ${ }^{9}$ Thus, stroke prevention in SCD children must begin early in life.

The results from this analysis have significant implications for the clinical management of children with SCD. An early study showed that children with SCD who had experienced neurological damage from a stroke never regained the intellectual and neurological status that they had prior to the stroke. ${ }^{5}$ If sickle cell related stroke can be prevented, the devastating disability caused by stroke among these children will be significantly reduced. Consequently, the clinical management of children with SCD should include carefully monitoring for stroke risk factors. Such risk factors have been explored in children with SCD and include increased systolic blood pressure, transient ischemic attacks, low hemoglobin concentrations, and acute chest syndrome episodes. ${ }^{4}$ In addition, a recent study has also identified risk factors for silent cerebral infarctions. These risk factors include low rate of painful events, a history of seizures, increased leukocyte count and the Senegal $\beta^{\mathrm{s}}$ globin haplotype. ${ }^{8}$ For years, blood transfusion has been the standard of care for prevention of recurrent strokes. Recently, it has been shown that transfusion regimens are also successful in the primary prevention of stroke. ${ }^{20}$ However, currently recognized risk factors do not have great predictive power and prevention therapies, such as blood transfusions, carry significant health risks. ${ }^{21,22}$ Nonetheless, given the magnitude of the association between SCD and DD with stroke, the impact stroke has on the lives of children with SCD, their families, and the community cannot be ignored. Thus, we must work to identify risk factors with better predictive power and safer preventive therapies than are currently available.

The role of sociodemographic factors in the association between SCD and DD is unclear. A positive association between maternal education and academic and neuropsychological outcomes of children with SCD had been previously reported. ${ }^{23}$ However, we did not detect this association in our own data. Additionally, other analyses of the MADDSP population indicated that mothers who are 35 years or older are at increased risk of having children with MR when compared with mothers who are younger (CA Boyle, unpublished data). The present analysis of the MADDSP population suggested a trend which indicates that children with SCD born to older mothers have a slightly increased risk for DD than those born to younger mothers, but the trend was not statistically significant. Most likely, the results from this analysis suffered from low power due to the small number of children born to older mothers $(N=141)$ in our population. Thus, the role of sociodemographic factors in the association between SCD and DD requires additional investigation. We should also note that there was a preponderance of male SCD cases. However, this was also true for the entire DD population. The proportion of male SCD cases was $64 \%$ and for the entire DD population, the proportion of males was $63 \%$. Thus, factors independent of SCD must contribute to the preponderance of males with DD.

To our knowledge, the present analysis is the first population-based study that has measured the contribution of SCD to the occurrence of DD among black children. The populationbased design of the study was strengthened by careful and complete ascertainment of DD outcomes. However, as with most analyses, there were also weaknesses. First, the frequency of SCD in this population had to be estimated. State newborn screening estimates of black children born in metropolitan Atlanta during the appropriate years were incomplete since the state of Georgia did not perform universal screening. ${ }^{24}$ Instead, we used a national estimate of the prevalence of SCD. ${ }^{2}$ However, even if this estimate of our population prevalence is somewhat inaccurate, it still would not affect our findings because of the large Obs/Exp ratio (130) for stroke-related DD among children with SCD. A second weakness of the study is that the genotype results ( $\mathrm{Hb} \mathrm{SS}, \mathrm{Hb}$ SC, etc) were not available 
for the children in the analysis. Because this information was not available, we cannot make inferences about genotype-phenotype correlations. However, we suspect, due to the severity of disease among the children with SCD in our population, that most are homozygous for $\mathrm{Hb} \mathrm{S}$. Children homozygous for $\mathrm{Hb} S$ have a more severe course of disease ${ }^{1}$ and have the highest rates of stroke among children with SCD. ${ }^{4-6}$ Finally, we were unable to contact the children with SCD and perform additional examinations such as MRIs and more extensive neurological tests. Thus, we were unable to detect silent cerebral infarction and to correlate specific disabilities with detailed diagnostic results. However, even with these limitations, we were able to demonstrate clearly that neurological damage is associated with stroke among children with SCD.

In conclusion, we have shown that children with SCD are at a much greater risk for DD than would be expected in our population and that this increased risk appears to be almost entirely associated with the occurrence of stroke. Since there are identifiable risk factors and preventive measures for strokes among children with SCD, the morbidity and disability due to SCD related stroke can be significantly reduced. These interventions have the potential to be as effective at reducing morbidity as was penicillin prophylaxis in reducing mortality among children with SCD.

\section{Acknowledgments}

This work was funded by the Centers for Disease Control and Prevention, in part through a cooperative agreement with the Association of Teachers of Preventive Medicine.

\section{References}

1. Gill FM, Sleeper LA, Weiner SJ, Brown AK, Bellevue R, Grover R, Pegelow CH, Vichinsky E. Clinical events in the first decade in a cohort of infants with sickle cell disease. The Cooperative Study of Sickle Cell Disease. Blood 1995;86:776-783.

2. Sickle Cell Disease Guideline Panel. Sickle cell disease: screening, diagnosis, management, and counseling in newborns and infants. Clinical Practice Guideline No. 6. AHCPR Pub. No. 93-0562. Rockville, MD: Agency for Health Care Policy and Research, Public Health Service, U.S. Department of Health and Human Services, April, 1993.

3. Adams RJ, McKie VC, Carl EM, Nichols FT, Perry R, Brock K, McKie K, Figueroa R, Litaker M, Weiner S, Brambilla D. Long-term stroke risk in children with sickle cell disease screened with transcranial doppler. Ann Neurol 1997;42:699-704.

4. Ohene-Frempong K, Weiner SJ, Sleeper LA, Miller ST, Embury S, Moohr JW, Wethers DL, Pegelow CH, Gill FM. Cerebrovascular accidents in sickle cell disease: rates and risk factors. Blood 1998;91:288-294.
5. Powars D, Wilson B, Imbus C, Pegelow C, Allen J. The natural history of stroke in sickle cell disease. Am J Med 1978;65:461-471.

6. Armstrong FD, Thompson RJ Jr, Wang W, Zimmerman R, Pegelow CH, Miller S, Moser F, Bello J, Hurtig A, Vass K. Cognitive functioning and brain magnetic resonance imaging in children with sickle cell disease. Pediatrics 1996;97:864-870.

7. Balkaran B, Char G, Morris JS, Thomas PW, Serjeant BE, Serjeant GR. Stroke in a cohort of patients with homozygous sickle cell disease. J Pediatr 1992;120:360-366.

8. Kinney TR, Sleeper LA, Wang WC, Zimmerman RA, Pegelow CH, Ohene-Frempong K, Wethers DL, Bello JA, Vichinsky EP, Moser FG, Gallagher DM, DeBaun MR, Platt OS, Miller ST. Silent cerebral infarcts in sickle cell anemia: a risk factor analysis. The Cooperative Study of Sickle Cell Disease Pediatrics 1999;103:640 -645.

9. Wang WC, Langston JW, Steen RG, Wynn LW, Mulhern RK, Wilimas JA, Kim FM, Figueroa RE. Abnormalities of the central nervous system in very young children with sickle cell anemia. J Pediatr 1998;132:994-998.

10. Hindmarsh PC, Brozovic M, Brook CGD, Davies SC. Incidence of overt and covert neurological damage in children with sickle cell disease. Postgrad Med J 1987;63: 751-753.

11. Craft S, Schatz J, Glauser TA, Lee B, DeBaun MR. Neuropsychologic effects of stroke in children with sickle cell anemia. J Pediatr 1993;123:712-717.

12. Hariman LM, Griffith ER, Hurtig AL, Keehn MT. Functional outcomes of children with sickle-cell disease affected by stroke. Arch Phys Med Rehabil 1991;72:498-502.

13. Wasserman AL, Wilimas JA, Fairclough DL, Mulhern RK, Wang W. Subtle neuropsychological deficits in children with sickle cell disease. Am J Pediatr Hematol Oncol 1991;13:14-20.

14. Swift AV, Cohen MJ, Hynd GW, Wisenbaker JM, McKie KM, Makari G, McKie VC. Neuropsychologic impairment in children with sickle cell anemia. Pediatrics 1989; 84:1077-1085.

15. Steen RG, Xiong X, Mulhern RK, Langston JW, Wang WC. Subtle brain abnormalities in children with sickle cell disease: relationship to blood hematocrit. Ann Neurol 1999;45:279-286.

16. Boyle CA, Yeargin-Allsopp M, Doernberg NS, Holmgreen P, Murphy CC, Schendel DE. Prevalence of selected developmental disabilities in children 3-10 years of age: the Metropolitan Atlanta Developmental Disabilities Program, 1991. MMWR CDC Surveill Summ 1996;45:1-14.

17. James LM. Statistical Analysis Battery for Epidemiologic Research (SABER). Version 1.96. Atlanta: Centers for Disease Control and Prevention (CDC) 1996.

18. Miettinen OS. Proportion of disease caused or prevented by a given exposure, trait or intervention. Am J Epidemiol 1974;99:325-332.

19. Davis H, Gergen PJ, Moore RM Jr. Geographic differences in mortality of young children with sickle cell disease in the United States. Public Health Rep 1997;112: $52-8$.

20. Adams RJ, McKie VC, Hsu L, Files B, Vichinsky E, Pegelow C, Abboud M, Gallagher D, Kutlar A, Nichols FT, Bonds DR, Brambilla D. Prevention of a first stroke by transfusions in children with sickle cell anemia and abnormal results on transcranial doppler ultrasonography. N Engl J Med 1998;339:5-11.

21. Cohen AR. Sickle cell disease: new treatments, new questions. N Engl J Med 1998; 339:42-44.

22. Sarnaik SA. Prevention of stroke by transfusions in children with sickle cell anemia. N Engl J Med 1998;339:1477-1478.

23. Fowler MG, Whitt JK, Lallinger RR, Nash KB, Atkinson SS, Wells RJ, McMillan C. Neuropsychologic and academic functioning of children with sickle cell anemia. J Dev Behav Pediatr 1988;9:213-220.

24. The Council of Regional Networks for Genetic Services (CORN). Newborn Screening Report for 1990. New York: CORN, 1992. 